\title{
Aspects of the cadets' mental readiness forming during airborne training
}

\author{
Oleg Labeschenkov ${ }^{* 1}$, Zinaida Kuznetsova ${ }^{2}$, Fanavi Zekrin ${ }^{2}$, Svetlana Komarova ${ }^{3}$, Elena Kuznetsova ${ }^{4}$ \\ ${ }^{1}$ Tyumen Higher Military Engineering Command school (Military Institute) named after Marshal of engineering troops A.I. \\ Proshlyakov», 625001, Tyumen, Russia \\ ${ }^{2}$ Tchaikovskiy State Institute of Physical Culture, 617764, Tchaikovskiy, Russia \\ ${ }^{3}$ Olympic Reserve Sports School No. 11, 423803, Naberezhnye Chelny, Russia \\ ${ }^{4}$ University of Management "TISBI”, 423806, Naberezhnye Chelny, Russia
}

\begin{abstract}
The mental readiness formation of cadets' airborne training in military universities require a special attitude to the functional state indicators. There is a need to develop a specialized method of mental state psychoregulation. The mental readiness formation requires the study of pedagogical, psychological and physiological foundations. A questionnaire survey of the psychoregulation means importance for airborne training was conducted. The cadets give ambiguous answers to the questions of their mental state psychoregulation in airborne training. The first-year cadets have little idea about the mental readiness state, about the means of its regulation. The study of the functional state and body reserve capabilities with the use of innovative accessible and operational methods of rapid diagnostics allows correction of training and psychological effects on cadets. Taking into account physical, mental, and training loads and the tendency to increase them in airborne training requires current and operational control of the functional state. Options for including multidirectional exercises of the mental state psychoregulation in combination with audio sessions on M. A. Bendyukov method in the process of airborne training are considered.
\end{abstract}

\section{Introduction}

Mental readiness in the cadets' professional activity of military universities is considered as a readiness condition to perform military professional tasks. The success in cadets' military activities depends on the complex manifestation of the physical, mental, emotional and functional components of any training. The mental training of cadets should be planned within the framework of integrated training.

Physical and mental loads during cadets' airborne training often lead to physical and emotional overload, which leads to a decrease in general and special physical performance $[1,2,3,4,5,6]$. Experts explain this situation by the low level of general physical fitness of applicants. The first-year students meet regulatory requirements, and when performing specialized exercises, they show low indicators. They characterize a low level of functional readiness. Consequently, athletes and cadets pay little attention to the functional components of physical training $[7,8]$.

Mikhalina O. S., Dementiev V. L. in their works consider the automated methods use of autogenic training as a condition for the formation and regulation of pre-start states of athletes [7]. M. V. Nikityuk (2014) theoretically justified the effectiveness of the Greco-Roman wrestlers' training method. He took into account their bioenergetic profile, which allowed to increase the energy capabilities of the body [8].

\section{Materials and methods}

The experimental base for the research was the Tyumen Higher Military Engineering Command school (Military Institute) named after Marshal of engineering troops A. I. Proshlyakov. The cadets aged 17-19 years took part in the research.

Analysis of scientific and methodological literature related to the study of the cadets and athletes training features, their physical and mental state in extreme conditions with overcoming large and significant physical loads of various directions.

A questionnaire survey was conducted to identify the attitude of cadets to the formation of a mental readiness state for airborne training. The attitude to the inclusion of various means of psychoregulation and self - regulation was key in the questionnaire survey. The questionnaire survey of cadets was attended by cadets of all levels of

\footnotetext{
* Corresponding author: Labeshenkova@yandex.ru
} 
training in the number of 60 people (first year 17 people, 2nd year 19 people, 3rd year 24 people and 4 th year 15 people). The study was conducted in the period 2015-2017).

\section{Results and discussion}

The analysis of key issues related to the cadets' mental readiness and the means used for psychoregulation in airborne training is carried out. The results of the questionnaire survey of cadets are presented in table 1.

]Table 1. The questionnaire survey results for cadets in course 1-4.

\begin{tabular}{|c|c|c|c|c|c|c|c|c|}
\hline \multirow[t]{3}{*}{ Key questions } & \multicolumn{8}{|c|}{ Study groups and response options } \\
\hline & \multicolumn{2}{|c|}{1 course $(n=17)$} & \multicolumn{2}{|c|}{2 course $(n=17)$} & \multicolumn{2}{|c|}{3 course $(n=18)$} & \multicolumn{2}{|c|}{4 course $(n=13)$} \\
\hline & Yes & No & Yes & No & Yes & No & Yes & No \\
\hline $\begin{array}{l}\text { Do you know about the state of } \\
\text { mental readiness? }\end{array}$ & $5(29,4 \%)$ & $\begin{array}{c}12 \\
(70,6 \%)\end{array}$ & $5(29,4 \%)$ & $\begin{array}{c}12 \\
(70,6 \%)\end{array}$ & $\begin{array}{c}10 \\
(58,2 \%)\end{array}$ & $\begin{array}{c}8 \\
(47 \%) \\
\end{array}$ & $\begin{array}{c}10 \\
(76,9 \%)\end{array}$ & $\begin{array}{c}3 \\
(23,1 \%) \\
\end{array}$ \\
\hline \multicolumn{9}{|l|}{$\begin{array}{l}\text { Tools and methods used in } \\
\text { psychoregulation: } \\
\text { 1) auto-training; }\end{array}$} \\
\hline $\begin{array}{l}\text { 2) sleep; } \\
\text { 3) music; }\end{array}$ & $\begin{array}{c}2 \\
(17,8 \%)\end{array}$ & 0 & $\begin{array}{c}3 \\
(17,6 \%) \\
\end{array}$ & 0 & $6(33,3 \%)$ & 0 & $5(38,5 \%)$ & 0 \\
\hline 4) meditation; & 0 & $3(17,6 \%)$ & $2(11,8 \%)$ & $3(17,6 \%)$ & $1(5,55 \%)$ & 0 & 0 & 0 \\
\hline \multirow[t]{3}{*}{ 5) exercises } & $2(11,8 \%)$ & $1(5,9 \%)$ & $2(11,8 \%)$ & & $3(16,7 \%)$ & 0 & $3(23,0 \%)$ & 0 \\
\hline & $1(5,9 \%)$ & $1(5,9 \%)$ & $1(5,9 \%)$ & $4(23,5 \%)$ & $5(27,8 \%)$ & 0 & $5(38,5 \%)$ & 0 \\
\hline & $3(17,6 \%)$ & $4(23,5 \%)$ & $2(11,8 \%)$ & & $3(16,7 \%)$ & $\overline{0}$ & 0 & 0 \\
\hline \multirow{4}{*}{$\begin{array}{l}\text { What is the main thing in a } \\
\text { mental readiness state: } \\
\text { 1) motivation; } \\
\text { 2) specialist; } \\
\text { 3)training. }\end{array}$} & & & & & & & & \\
\hline & $\begin{array}{c}10 \\
(58,8 \%) \\
\end{array}$ & 0 & $\begin{array}{c}12 \\
(70,6 \%) \\
\end{array}$ & 0 & $\begin{array}{c}10 \\
(55,5 \%) \\
\end{array}$ & 0 & 0 & 0 \\
\hline & $2(11,8 \%)$ & 0 & $\begin{array}{c}3 \\
(17,6 \%) \\
\end{array}$ & 0 & $\begin{array}{c}3 \\
(16,7 \%) \\
\end{array}$ & 0 & 0 & 0 \\
\hline & $5(29,4 \%)$ & 0 & $\begin{array}{c}2 \\
(11,8 \%) \\
\end{array}$ & 0 & $\begin{array}{c}5 \\
(27,8 \%) \\
\end{array}$ & 0 & $\begin{array}{c}13 \\
(100 \%) \\
\end{array}$ & 0 \\
\hline
\end{tabular}

Table 1 shows that first-and second-year students have mixed opinions about their mental readiness state. $29.4 \%$ of first-and second-year cadets answered that they know about the mental readiness state, as a manifestation of the psychological state before the start. $70.6 \%$ of first-and second-year cadets could not answer this question. Third-year $(58.2 \%)$ and fourth-year $(76.9 \%)$ cadets said they were aware of the mental readiness state. Among them were also cadets who had no idea about the mental readiness state. But when they deciphered the concept as one of the components of psychological training, they showed that they had an idea.

To the question of "Means and methods used in psychoregulation: 1) auto-training; 2) sleep; 3) music; 4) meditation; 5) exercises" responses were divided depending on the means of psychoregulation (Table.1). It is noted that the students are aware of the psychoregulation means their mental condition. In the first place, the cadets of all four courses put meditation and then self-training, as components of changing the psychoemotional state.

To the question "What is the main thing in the state of mental readiness: 1) motivation; 2) specialist; 3) training", the cadets of all courses answered that they knew about the mental readiness state and linked it with motivation and the training process. Therefore, motivation in the cadets' military training process was the main forming correlate of their attitude to their profession.

A comparative analysis of the questionnaire results allowed to note the need to determine the time for studying the issue related to psychological training and the use of psychoregulation tools in preparing oneself for airborne training.

The specialists developed a method of cadets' mental state psychoregulation to perform military amphibious training. An important component of this technique was the use of audio sessions by M. A. Bendyukov method before and after the parachute jump. They also used a calming version of audio sessions to activate recovery processes, neuropsychic recovery. The sessions lasted from 5 minutes to 20 minutes. Before the parachute jump sessions were repeated with a duration of up to 30 minutes for the first course; for the second year - up to 25 minutes; for the third year-up to 20 minutes and for the fourth year - 10-15 minutes.

The effectiveness of teaching autogenic training techniques using video sessions of mental state self - regulation increases if they are used regularly 2-3 times a week after intensive training loads in order to restore performance and psychoemotional state.

An important component of psychoregulatory training before skydiving is the use of exercises aimed at disabling the psyche.

The training complex of cadets airborne training from the first to the fourth year included exercises for attention, memorizing various subjects, focusing on abdominal breathing, focusing on tension and relaxation of various muscle groups. All these exercises were implemented in combination with an audio session. 
Audio sessions are aimed at activating the recovery processes and neuropsychic state of the cadets ' body. The duration was from 5 minutes to 20 minutes, up to 30 minutes.

There is mental tension (contraction of the facial muscles, frowning eyebrows, compressed mouth, which causes involuntary tension of many muscles). It is very often during concentration. In sports practice such tension interferes. In military activities, it is very important to be able to perform many things, including extremely focused, without straining.

When using breathing exercises (abdominal or diaphragmatic breathing), inhale is for 2 counts, exhale - for 4 , pause - for 2. If you need to mobilize, excite yourself, we recommend to build your breathing: stretching the breath to count 4 , pause until count 2 and a sharp exhalation to count 2 . When you inhale, you should half - strain the muscles (arms and legs), and when you exhale, relax them and listen to the sensations that arise.

These exercises were implemented during four training courses. The exercises were repeated taking into account the operational state of the cadets. It was determined during the conversation before the parachute jump.

The study of the functional state and reserve cadets ' body capabilities with the use of innovative accessible and operational methods of functional state rapid diagnostics, especially the capacity, power and efficiency of the muscular system energy supply, allows to correct the training and psychological effects. Changes in the capacity, efficiency, and power of energy supply indicators were noted. In subsequent publications, we will present indicators of the functional state and cadets ' body reserve capabilities over the course of several years.

Indicators of the body's functional state are the key to the formation of an effective mental readiness state before a jump and the effectiveness correlate of parachute training.

\section{Conclusions}

The results of the questionnaire showed that the problem of psychoregulation or cadets' mental readiness state before preparing for a jump is an important component of airborne training. Systematic use of psychoregulatory training in the course of cadets' airborne training allows to reduced performance by improving the body recovery processes with the inclusion of a mental component. It is important to expand the energy supply mechanisms for muscle activity using large and significant physical loads.

\section{References}

1. V.V. Barabanschikova, A.S. Kuznetsov, Innovative technologies in martial arts (Moscow, 2004)

2. V.V. Borodin, V.I. Ermolaeva, Actual problems of Humanities and socio-economic Sciences, 3, 66-72 (2014)

3. B.A. Vyatkin, Management of mental stress in sports competition (Physical culture and sport, M., 1981)

4. S.A. Dushanin, U.V. Beregovoy, V.G. Miguleva, Accelerated methods for studying the energy metabolism of muscle activity: Guidelines (Kiev, 1984)

5. Z.M. Kuznetsova, A.V. Ryabchuk, O.V. Labeschenkov, The Russian Journal of Physical Education and Sport, 13(2), 198206 (2018). DOI: 10.14526/02_2018_326

6. A.S. Lesnev, Influence of psychological factors on sports result (Moscow, 2002)

7. O.S. Mikhalina, V.L. Dementiev, Innovative technologies in martial arts (Moscow, 2004)

8. M.V. Nikityuk, Pedagogico-psychological and medico-biological problems of physical culture and sport, 9(3), 47-53 (2014). URL: http://kamgifk.ru/magazin/journal.htm. 